\title{
Recados descolonizadores desde la Mapurbe: Daniela Catrileo, Camila Huenchumil y Daniela Millaleo ${ }^{1}$
}

\author{
Decolonizing recados from the Mapurbe: \\ Daniela Catrileo, Camila Huenchumil and Daniela Millaleo
}

\author{
MARÍA JOSÉ BARROS CRUZ \\ ${ }^{a}$ Universidad Adolfo Ibáñez. \\ Correo electrónico: maria.barros@uai.cl
}

\begin{abstract}
En el artículo se analizan los trabajos recientes de tres artistas mapuche: el poemario Río herido de Daniela Catrileo, la performance Warriache de Camila Huenchumil y los discos Trafun y Wanglen de Daniela Millaleo. Propongo leer estas producciones como recados descolonizadores que representan las consecuencias del desarraigo y el exilio forzado desde Wallmapu a la periferia urbana en el contexto de la postdictadura chilena. Desde distintas miradas y soportes artísticos, las tres artistas reconstruyen su lugar de pertenencia en la ciudad como mujeres mapuche en resistencia, elaborando discursividades chixi (Rivera) que tensionan la pregunta acerca de la identidad indígena.
\end{abstract}

Palabras claves: arte mapuche, descolonización, ciudad, mestizaje.

Recent works from three Mapuche artists are analyzed in the article: the collection of poems Rio herido by Daniela Catrileo, the performance Warriache by Camila Huenchumil, and the albums Trafun and Wanglen by Daniela Millaleo. I propose reading these productions as decolonizing recados that represents the consequences of the uprooting and forced exile from Wallmapu to the urban periphery, set against the backdrop of post-dictatorial Chile. The three artists reconstruct their place of belonging in the city as Mapuche women in resistance from different viewpoints and through different artistic formats, thus creating chixi (Rivera) discourses that place tension on the question surrounding indigenous identity.

Key words: Mapuche art, descolonization, city, mestizaje.

\footnotetext{
${ }^{1}$ Este artículo se enmarca en el proyecto postdoctoral Fondecyt 3180228 "Artistas y activistas del siglo XXI: retóricas de la resistencia y genealogías descolonizadoras en Cecilia Vicuña, Ana Tijoux y Camila Huenchumil" (2018-2020), del cual soy la investigadora responsable. Además, parte de las ideas aquí compartidas se nutren de las reflexiones y conversaciones sostenidas con mis amigos y colegas del colectivo Recados Verdes, a quienes debo también el título de este ensayo.
} 


\section{INTRODUCCIÓN: CREAR Y RESISTIR DESDE LA MAPURBE}

En el año 2005, el poeta David Aniñir publicó su primer libro, Mapurbe venganza a raíz, en una edición autogestionada y comercializada por él mismo, cuya manufactura artesanal anunciaba desde un comienzo la estética punk, urbana y marginal de su escritura. Este poemario, que ya cuenta con una reedición de la editorial Pehuén y varias publicaciones académicas a su haber, provocó un giro en el campo de la poesía mapuche de las últimas décadas. Mientras autores más canónicos como Elicura Chihuailaf o Leonel Lienlaf elaboraban una narrativa identitaria anclada en la tradición y las tierras ancestrales, Aniñir nos invitaba a pensar la identidad cultural desde un nuevo escenario de enunciación: los barrios periféricos de Santiago de Chile. "Somos mapuche de hormigón" (75), decía la voz en el poema "Mapurbe", poniendo de relieve la experiencia de exilio y precarización de los mapuche nacidos en la ciudad, pero también la posibilidad de reescribir la identidad indígena desde un espacio de hibridez cultural abierto al cruce entre lo local y lo global (Barros 2009). Desde entonces, el concepto de mapurbe inaugurado por Aniñir se ha convertido en un neologismo literario y político crucial en el proceso de autorreconocimiento identitario de los mapuche urbanos. Como bien explica Claudia Zapata, esta es una "categoría que nombra una experiencia, una memoria, un espacio y un presente, la que es utilizada por militantes, intelectuales, activistas y por una amplia red social y cultural" (78).

En los últimos años, una nueva generación de jóvenes artistas mapuche, situados en distintas ciudades del país, han vuelto a relevar la experiencia de los mapuche urbanos como un eje fundamental de sus proyectos creativos y activismos ${ }^{2}$. Estamos hablando de escritores, artistas visuales, performers, cantautores y raperos que encuentran su genealogía en el concepto de mapurbe, pero que, al mismo tiempo, han resignificado la propuesta de Aniñir desde disciplinas y soportes artísticos que trascienden lo literario, con una mirada de género atenta a los feminismos indígenas y las disidencias sexuales. Considerando esta nueva escena artística-cultural, nos proponemos abordar en este ensayo algunas producciones recientes de la poeta Daniela Catrileo, la actriz Camila Huenchumil y la cantautora Daniela Millaleo. Todas artistas mapuche nacidas en Santiago a fines de los años 80, quienes convergen en la elaboración de un lugar de enunciación marcado por su condición de habitantes de la waria y la reivindicación de la ciudad como un territorio en disputa desde el cual reconstruyen sus historias de exilio, migración y pertenencia.

En línea con lo anterior, propongo leer el poemario Río herido (2016) de Catrileo, la serie de performances Warriache (2015-2019) de Huenchumil y los discos Trafun (2013) y Wanglen (inédito) de Millaleo como recados descolonizadores que representan las consecuencias del desarraigo y el exilio forzado desde Wallmapu a la periferia urbana

\footnotetext{
${ }^{2}$ Además de las artistas incluidas en este artículo, pienso en figuras como Sebastián Calfuqueo, Paula Baeza Pailamilla y Francisco Vargas Huaiquimilla en el ámbito de la performance, las artes visuales y la poesía, así como en los raperos Waikil y Luanko, entre otros.
} 
en el contexto de la postdictadura chilena ${ }^{3}$. Frente a las experiencias de la pérdida y el despojo ocasionadas por la diáspora mapuche (Mariman et al. 261), Catrileo, Huenchumil y Millaleo reconstruyen su lugar de pertenencia en la ciudad como mujeres mapuche en resistencia, elaborando discursividades abigarradamente mestizas o chixi en las que se entrelazan, chocan y coexisten memorias, voces, saberes, lenguas y referentes culturales heterogéneos. De ahí, entonces, la posibilidad de leer estas producciones en diálogo con los recados, género de la oralidad, lo cotidiano y lo comunitario, resignificado tempranamente por Gabriela Mistral en su prosa periodística (Morales 2011), y que nos remite a una textualidad híbrida habitada por hablas y relatos tanto propios como ajenos. Algo similar ocurre en los trabajos de las artistas que aquí nos convocan. En sus obras podemos rastrear las huellas de una comunidad diezmada por la violencia colonial y el desplazamiento migratorio, cuyas memorias, historias y filiaciones son reconstruidas e imaginadas desde el espacio de la ciudad. Una ciudad que es pensada como un territorio propio, habitada desde los márgenes, y capaz de dotar de identidad y sentido de pertenencia a las y los warriache.

Con respecto a lo chixi, retomamos este concepto de Silvia Rivera Cusicanqui, sociológa y activista boliviana, quien toma prestada esta palabra de la lengua y cultura aymara:

hay que recordar el significado de la palabra chixi: simplemente designa en aymara a un tipo de tonalidad gris. Se trata de un color que por efecto de la distancia se ve gris, pero al acercarnos nos percatamos de que está hecho de color puro y agónico: manchas blancas y negras entreveradas. [...] También ciertas piedras son chíixi: la andesita, el granito, que tienen texturas de colores entreverados en manchas diminutas (79).

A partir de este término que le fue enseñado por el escultor Víctor Zapana, en los últimos años Rivera Cusicanqui ha venido desarrollando su epistemología chixi, teoría y práctica desde la cual propone repensar la noción de mestizaje en el mundo andino actual. Consciente de la multiplicidad y densidad espacio-temporal de nuestras sociedades latinoamericanas y la "fisura colonial" (81) que habita en cada uno, lo chixi opera como un concepto-metáfora para pensar un mestizaje que, lejos de la nociones neutralizadoras de multiculturalismo (Mignolo) e hibridez (García Canclini), es entendido como una fuerza

\footnotetext{
${ }^{3}$ Siguiendo al historiador Enrique Antileo, la migración mapuche de los siglos XX y XXI no puede ser entendida como "un proceso voluntario derivado de decisiones libres y sin presiones. Todo lo contrario, la llegada de la población Mapuche a ciudades en el mismo Wallmapu o fuera de él (como el caso de Santiago), obedece a factores estructurales de dominación, que se transforman constantemente, pero cuya conformación colonial sigue vigente" (187). Por cierto, esta lectura colonial acerca de los desplazamientos recientes del pueblo mapuche a la ciudad se nutre de los planteamientos de Pablo Mariman, Sergio Caniqueo, José Millalén y Rodrigo Levil, historiadores que en su emblemático libro j...Escucha Winka...! proponen entender este movimiento migratorio a partir del concepto de diáspora: "Desde una perspectiva política podríamos referirnos a la diáspora Mapuche como la población forzada a abandonar el Wallmapu, su territorio nacional, por medios políticos y económicos principalmente" (261, cursivas en el original).
} 
descolonizadora y emancipadora. Así, y en coherencia con el cromatismo impuro al que refiere la palabra chixi, Rivera Cusicanqui cuestiona la lógica de los dualismos excluyentes y aboga por una construcción identitaria capaz de reconocer la oposición conflictiva entre lo indígena y lo europeo y abrir paso a la superposición de filiciones culturales divergentes: “ipor qué tenemos que hacer de todas contradicciones una disyuntiva paralizante? ¿Por qué tenemos que enfrentarla como una oposición irreductible? O esto o lo otro. En los hechos estamos caminando por un terreno donde ambas cosas se entreveran y no es necesario optar a rajatabla por lo uno o lo otro" (80).

Desde esta perspectiva, el mestizaje chíxi conceptualizado por Rivera Cusicanqui establece una clara distancia con la ideología oficial del mestizaje promovida por los Estadosnaciones del continente y sus elites durante el siglo XX. Siguiendo al académico boliviano Javier Sanjinés, ya no estamos hablando del mestizaje como un discurso dominante elaborado por los intelectuales de su país para oponerse a los sectores indígenas o bien cooptarlos en aras de su asimilación al proyecto nacional oficial (3), sino de un ejecicio de descolonización permanente, personal y colectivo, al que todas y todos estamos convocados. En palabras de Rivera Cusicanqui, este debe ser entendido como:

un proceso autoconsciente de descolonización que, sin (re)negar o evadirse de la fisura colonial, sea capaz de articular pasados y presentes indios, femininos y comunitarios en un tejido chixi, un mestizaje explosivo y reverberante, energizado por la fricción, que nos impulse a sacudir y subvertir los mandatos coloniales de la parodia, la sumisión y el silencio (87).

Sobre la base de lo anterior, he propuesto abordar los proyectos creativos de Catrileo, Huenchumil y Millaleo como recados descolonizadores que movilizan imaginarios, voces y subjetividades afines al mestizaje chixi de Rivera Cusicanqui, tensionando de esta manera las fantasías arcaizantes y esencialistas en torno al pueblo mapuche sostenidas por el Estado-nación chileno. En este sentido, me parece importante mencionar la noción de champurria que emerge desde el mismo pensamiento mapuche y que, en línea con lo planteado por la intelectual boliviana-aymara, también nos habla de la voluntad de pensar las identidades indígenas desde un posicionamiento situado en el presente histórico y abierto a los cruces y contradicciones que inevitablemente surgen con la experiencia colonial y la diáspora ${ }^{4}$.

Efectivamente, en últimos años la noción de champurria ha adquirido fuerza en el campo intelectual y cultural mapuche como un lugar intersticial, no purista y performativo desde el cual pensar las identidades y escrituras mapuche vinculadas especialmente a la

\footnotetext{
${ }^{4}$ En la charla Oralidad e insurgencia cotidiana dictada por Rivera Cusicanqui en la Universidad Academia de Humanismo Cristiano el 19 de enero de 2018, ella misma establece un símil entre su concepto del mestizaje chixi y lo champurria. El video completo de esta presentación organizada por el Centro de Estudios Interculturales e Indígenas (CIIR) se puede ver en el siguiente enlace: https://www.youtube.com/watch?v=lkWkjk10BWA
} 
ciudad. Probablemente, una de las primeras en articular su literatura desde dicho concepto fue la poeta Adriana Paredes Pinda. En el texto introductorio de Üi (2005), su primer libro, la escritora mapuche se refiere al ultraje lingüístico sufrido por su pueblo y reflexiona sobre la doble filiación que marca su poesía, tensionada entre la escritura y el canto, el español y el mapudungun, el mundo huinca y el mundo mapuche: "escribo porque tal vez es cierto que tengo dos corazones [...]. Escribo porque seguro no puedo cantar; si cantara solo tendría un piuke $[. .$.$] no logro zafarme del hechizo de esta escritura huinca porque me arranca y me$ arranca el aliento...” (2005: 7). Desde esta perspectiva, Paredes Pinda se define a sí misma en los siguientes términos: "Soy una mapuche champurria, "agua con harina" como dicen las papay, y hoy problematizo y enuncio desde esta condición existencial" (2017: 175). Así, escritores como Adriana Paredes Pinda, David Aniñir y Jaime Huenún, entre otros, abrieron paso a una nueva generación de escritores y artistas mapuche que hoy reivindican la ciudad y lo champurria como un lugar vital y creativo desde el cual posicionarse.

De acuerdo con Carla Llamunao, la palabra champurria solía tener una connotación más bien negativa en la sociedad mapuche; sin embargo, en el último tiempo, ha sido resignificada como un concepto que permite nombrar "una nueva identidad que admite el cruce entre lo colonial y lo mapuche" (158) y elaborar "un lugar de enunciación capaz de dialogar y generar reflexiones y demandas críticas frente a las nuevas violencias coloniales" (163). Daniela Catrileo, por ejemplo, en su ensayo breve "Merodeos en torno a la potencia champurria", propone entender este término como un "intersticio creativo y político" que, a diferencia de la versión homogeneizante del mestizaje de cuño nacionalista, busca revitalizar la fuerza contenida en "aquella hibridez, el nudo que nos dejó la diáspora" (s/p). Por su parte, el artista visual Sebastián Cafulqueo, en su instalación Mürke Ko (Agüita con harina tostada) (2016), reivindica lo champurria a partir de la figura de un sujeto inmóvil construido de tierra y resina, de cuya cabeza invertida emergen cabellos largos y sintéticos. La mezcla entre materiales orgánicos y artificiales, estáticos y en movimiento, así como el título de la obra, buscan "problematizar la existencia de una identidad que deba someterse a la pureza racial o definirse bajo cierto parámetro de binarismo: chileno o mapuche" $(\mathrm{s} / \mathrm{p})$, explica Calfuqueo. Todo lo anterior, sin duda, nos permite entender los recados de Catrileo, Huenchumil y Millaleo como producciones que emergen desde un lugar de enunciación champurria y, al mismo tiempo, como obras situadas y activamente políticas, que dialogan de manera estrecha con el actual contexto de criminalización y persecusión del movimiento mapuche que, desde 1990 hasta la fecha, lucha por el derecho a la autodeterminación (Pairicán 2014). En otras palabras, sus trabajos no pueden ser entendidos sin tener en cuenta el correlato histórico-político que actualmente marca el acontencer del pueblo mapuche ni la emergencia de lo champurria en la escena artística-cultural reciente.

Por último, y antes de proceder a analizar el corpus de Catrileo, Huenchumil y Millaleo, quisiera hacer mención al trabajo crítico realizado en torno a la producción de mujeres mapuche. Si bien estos estudios se centran exclusivamente en la literatura y por lo general en autoras que generacionalmente anteceden a las artistas que aquí estudiaremos, constituyen un aporte a la hora de situar estas producciones en el campo cultural mapuche- 
chileno e identificar sus particularidades contextuales y enunciativas. En este sentido, resulta importante señalar que la mayoría de las referencias críticas existentes hasta al momento en torno a Río herido, Warriache, Trafun y Wanglen son escasas y que en su mayoría corresponden a notas o reseñas de prensa centradas principalmente en la poesía de Catrileo. De ahí la necesidad de recurrir a la crítica que previamente ha pensado el arte femenino mapuche desde su literatura.

Dentro de la academia nacional, me parce importante destacar la investigación de Fernanda Moraga, quien se ha preocupado de sistematizar y analizar en distintos artículos la poesía contemporánea de mujeres mapuche, a lo que además se suma el libro Kümedugun/ Kümewirin. Antología poética de mujeres mapuche (siglos XX-XXI), editado junto con Maribel Mora Curriao, en el que se incluyen poemas y ülo cantos tradicionales. La académica sitúa la emergencia colectiva de este grupo de escritoras a inicios de los 90 y en estrecho vínculo con el protagonismo político que las mujeres indígenas adquieren en la última década del siglo XX (2010: 221). Reconociendo la diversidad de este corpus de escrituras, Moraga identifica cuatro estrategias discursivas y temáticas distintas: 1) el discurso político de contingencia; 2) el emplazamiento en una memoria ancestral; 3) la puesta en escena de enunciaciones conflictivas; 4) las propuestas poéticas que no apelan directamente a referentes culturales y sociales mapuche (2010: 243-4). De las estrategias recién mencionadas, la que resulta más significativa e iluminadora para efectos de nuestro trabajo es la tercera. Sobre esta, Moraga se ha detenido especialmente en la producción de las poetas mapuche-huilliche Roxana Miranda Rupailaf y Adriana Paredes Pinda, cuyos proyectos escriturales describe como poéticas en conflicto que presentan "cuerpos subjetivados en tensión" e "identidades problematizadas, mestizadas” (2009: 218).

Siguiendo la lectura de Moraga, me atrevo a pensar las escrituras de Miranda Rupailaf y Paredes Pinda -que se inician en la década del 2000- como un antecedente para ingresar en las producciones de Catrileo, Huenchumil y Millaleo. En libros como Las tentaciones de Eva (2003) y Üi (2005), respectivamente, estas poetas abren paso a la posibilidad de pensar, recrear y problematizar la identidad mapuche femenina desde un espacio cultural y lingüístico en permanente tensión y contradicción. Ya lo decíamos más arriba a propósito de Paredes Pinda y lo champurria. Ahora bien, en el caso de las artistas que aquí abordaremos, la ciudad y sus flujos culturales ocupan un papel fundamental que está prácticamente ausente en las poetas mapuche-huilliche analizadas por Moraga. Como ya lo hemos planteado al inicio de este trabajo, este diálogo crucial con el espacio urbano o la waria encuentra su antecedente, más bien, en la poesía de Aniñir y su concepto de mapurbe, aunque Catrileo, Huenchumil y Millaleo optan por trazar sus propios devenires urbanos y visibilizar las implicancias de habitar el territorio mestizado que es Santiago en su condición de mujeres warriache.

Sin más preámbulos, en los próximos apartados nos detendremos en el análisis de Rio herido de Catrileo, Warriache de Huenchumil y Trafun y Wanglen de Millaleo, buscando establecer las especificidades de estas producciones en relación con la experiencia de la diáspora mapuche y atendiendo, también, al soporte artístico en el que trabaja cada una. 


\section{Daniela Catrileo: escribir desde la herida}

Daniela Catrileo - escritora, profesora de filosofía e integrante del colectivo feminista mapuche Rangiñtulewfü-publicó por primera vez Río herido en el año 2013 con la editorial Libro del Perro Negro. Tres años después, ediciones Edicola publicó la versión definitiva del libro, que a juicio del crítico Felipe Poblete viene a "hacer justicia a la poesía que adentro se despliega”. Con esta publicación del 2016 Catrileo se convierte, poco a poco, en un referente fundamental de la nueva escena de escritores mapuche y producción poética de mujeres. De ello dan cuenta las distintas entrevistas publicadas en medios digitales alternativos y otros más conocidos como El Mostrador, así como su participación en múltiples eventos culturales y académicos tanto en Chile como en el extranjero, como la Feria Internacional del Libro de Lima o el Festival de PoetAs de Barcelona, ambos realizados en el año 2019.

Según lo explicado por Catrileo en la entrevista publicada por Biblioteca Viva, "El nombre del libro Río herido está dado por una traducción poética de mi apellido Catrileo (Katrü-lewfü), desde allí parto para relatar la migración mapuche a la periferia santiaguina que es mi historia familiar, no obstante, también es una historia común en la sociedad mapuche, que da lugar a la diáspora" (s/p). Este antecedente entregado por la escritora es importante para contextualizar una obra en la que se propone abordar la experiencia de la diáspora mapuche desde una perspectiva personal, familiar y colectiva, recurriendo para ello al resgitro de la poesía y los tropos del río y la herida presentes en su propio apellido. Lo anterior se visibiliza desde un comienzo en la portada de la edición del año 2016. En una ilustración simple y depurada, las ciudades de Santiago y Nueva Imperial -esta última ubicada en el corazón del Wallmapu- son apuntadas como referentes geográficos en medio de ríos y afluentes de color rojo y azul, elementos que funcionan como una antesala de los desplazamientos físicos e imaginados entre dos territorios distintos y los imaginarios del agua presentes en el texto.

El poemario se abre con la sección titulada Cesura: testimonio del accidente. Allí, la voz asume como propio el viaje de sus antecesores y se propone decir las secuelas de la migrancia situando su lugar de enunciación en medio del barrial y los blocks del Zanjón de la Aguada, sector popular ubicado en la zona sur de Santiago y que es atravesado por el caudal natural del mismo nombre, recordado por muchos capitalinos por sus desbordes e inundaciones. Al mismo tiempo, la hablante articula una reflexión metapoética en torno a la escritura y el lenguaje centrada en la metáfora múltiple del río y las aguas. Desde dicho posicionamiento vital y escritural, la sujeto inaugura su relato sobre la diáspora problematizando cualquier esencialismo y certeza sobre el origen, para luego indicarnos la hendidura del río como el lugar que habita y desde el cual emerge su habla mutilada:

No hay pureza

ni casa propia

en

el movimiento de las aguas

habitar 
el corte

sentenciada la boca

rota la lengua (Catrileo 13).

Al igual que los suyos, la voz poética lleva inscrita en su cuerpo la herida del exilio, idea que se elabora a lo largo del poemario mediante la repetición de palabras como "cesura", "corte", "rotura", "trozos", "tajo" y "fisura”, así como en la configuración de un discurso condensado y fragmentado, que reproduce tanto a nivel verbal como visual la imagen de una comunidad diezmada y silenciada. "Somos exilio / en la patria del río" (21), declara la voz algunas páginas más adelante, asumiendo un posicionamiento colectivo que remite a la experiencia del destierro vivida por una parte importante de la población mapuche y al río como la patria marginal de aquellos que han sido expulsados y despojados del territorio ancestral. De esta perspectiva, el río también es metaforizado a lo largo del poemario como una herida o un corte en la tierra, estableciéndose -como bien sostiene Patricia Espinosauna homologación entre sujeto, comunidad y paisaje. De alguna manera, este gesto nos retrotrae a las playas llagadas del Anteparaíso (1983) de Raúl Zurita, paisajes que en el contexto de la dictadura militar hacían eco de los cuerpos torturados y desaparecidos por la violencia de Estado. En el texto de Catrileo, el río es la herida que portan los mapuche urbanos exiliados en las riberas del Mapocho, el Zanjón de la Aguada y otros caudales que recorren las periferias de la capital.

Ahora bien, para los warriache forzados a vivir en esa zona fronteriza que son "los márgenes del río" (45), la herida también opera como una marca de la precariedad compartida. Así, en el relato que la voz poética construye acerca de su genealogía desterrada, nos hace saber que su padre decidió dejar atrás el sur producto de la pobreza rural; sin embargo, el viaje a la ciudad no ha hecho más que "mantener de pie / la pobreza" (48). Una pobreza dicha en las constantes referencias al "barro", la "ciénaga", la "acequia" y el "pozo", palabras que ponen de manifiesto la idea de un espacio al límite de lo rural y lo habitable, donde la urbanización es precaria y los blocks situados al borde del río coexisten con potreros, basurales y cuerpos en descomposición ${ }^{5}$. El río, entonces, es el lugar residual al que van a parar los desechos - no solo materiales, sino también vidas humanas- que nadie quiere ver. Es la contracara ominosa de una ciudad con edificios de espejos y autopistas como Santiago que, en el contexto de la transición democrática de los años 90, buscaba proyectar la imagen de una sociedad exitosa, recuperada del pasado traumático de la dictadura y abierta a los circuitos globales de los países desarrollados. Desde esta perspectiva, para la hablante de

\footnotetext{
${ }^{5}$ En las crónicas de Pedro Lemebel, el Zanjón de la Aguada de su infancia también es representado como un "opaco lodazal de la patria" (45). El escritor chileno reconstruye la historia de este lugar y sitúa sus orígenes a fines de los años 40, cuando las familias que emigraron desde el norte y el sur del país comenzaron a ocupar estos terrenos baldíos y periféricos ubicados en la zona sur de Santiago.
} 
Río herido la "conciencia del margen viene a constituirse como unidad-crisis determinante para su identidad" (Espinosa), a lo que además debemos agregar la consciencia de una racialización y discriminación que es compartida con los demás habitantes mapuche de las acequias y los barriales urbanos: "Tengo un río herido / en forma de zanjón / que grita india y me tira a la calle" (37). De esta manera, la voz da cuenta de la vigencia de la ideología colonial y patriarcal sobre la que se construyó la ciudad de Santiago, donde los cuerpos que se escapan de las fantasías blanqueadas de la comunidad nacional son expulsados a la periferia del zanjón e inferiorizados a partir de estereotipos racistas y sexistas como "india".

Pero además de la precariedad, la racialización y la discriminación, la herida del exilio dice relación con "la rotura / de la lengua" (20), es decir, con la pérdida del mapudungún y los conocimientos asociados a dicha forma de nombrar y pensar el mundo. Estamos hablando de un acto de violencia epistémica ejercido en primer lugar sobre los ancestros muertos, cuyas hablas censuradas convertidas en "aullidos" dejan entrever la herida de este despojo lingüístico: "Caminan sin lengua / aúllan / como réplicas del signo" (22). Catrileo deja testimonio en sus poemas de lo que la poeta Paredes Pinda ha llamado el ultraje de la lengua y la palabra (2005: 12), borradura que en la ciudad es internalizada violentamente en la escuela, tal como se aprecia en el texto "Aprendimos a leer a golpes": "Hasta negar la lengua. // La h muda se extiende al río / que tachaste con la herida" (46). Al igual que en el poema "Rebelión" de Leonel Lienlaf o el video clip "Nuestra historia mapuche" del rapero Waikil, el sistema educativo chileno es representado como una institución colonial y racista, donde los saberes indígenas son brutalmente negados y silenciados. Sin embargo, frente a esta colonización de los conocimientos, Catrileo buscará reterritorializarse en las aguas movedizas de la escritura, haciendo de la poesía una lengua propia ${ }^{6}$ desde la cual comenzar a decir las heridas de la diáspora y las memorias de "la familia esparcida" (49).

En este sentido, resulta importante mencionar que el proyecto escritural iniciado con Río herido tiene su continuidad en libros posteriores que, con sus propias particularidades, también abordan la experiencia migratoria mapuche, la vida en los márgenes de la ciudad y la (im)posibilidad del retorno. Me refiero a la colección de cuentos Piñen (2019), primera incursión de Catrileo en narrativa, y la plaquette del poemario Las aguas dejaron de unirse a otras aguas (2020), ambos publicados por la editorial Libros del Pez Espiral. En el caso de los tres relatos reunidos en Piñen, estos narran la experiencia de la periferia urbana desde la perspectiva de jóvenes adolescentes que, en medio de la pobreza, la violencia sexual, los

\footnotetext{
${ }^{6}$ En relación con la experiencia territorial y lingüística de los sujetos migrantes, me parece que el relato construido por Catrileo en Río herido acerca de la diáspora mapuche se aproxima a lo planteado por Gloria Anzaldúa en Borderlands/La Frontera. La nueva mestiza (1978). Allí, la escritora y activista mexicana comienza su defensa del español chicano recordando las reprimendas de su maestra por no hablar inglés en la escuela y las recriminaciones de los latinos más puristas que denostaban sus modismos spanglish. Consciente de esta situación de discriminación proveniente de lado y lado, Anzaldúa reivindica su "idioma fronterizo" como una "lengua salvaje", "viva" e "ilegítima" y sostiene que para muchos chicanos esta lengua disidente se convirtió en su única "patria" (103-11). Algo similar se deja entrever en el texto de Catrileo. Frente al despojo tanto territorial como cultural provocado por el destierro, la escritura se convierte en la "patria" para comenzar a echar raíces, deambular con soltura entre los afluentes de aquí y de allá, y suturar poco a poco la herida del exilio.
} 
imperativos religiosos y la discriminación, se autorreconocen como mapuche desde una rebeldía punk. Por su parte, los poemas de Las aguas dejaron de unirse a otras aguas recrean el viaje de dos hermanos a la casa de los abuelos en el lago Budi, poniendo en escena las tensiones, rituales cotidianos y afectos de esas tierras ancestrales en las que no les tocó nacer. Las heridas de la waria, entonces, se constituyen como un locus enunciativo que articula el proyecto escritural de Catrileo.

\section{Camila Huenchumil: el CUerpo como territorio}

Camila Huenchumil -actriz, directora de teatro y educadora- da inicio en el año 2015 a su proyecto performático Warriache. Esta serie de acciones artísticas comenzó como una investigación teatral y, desde entonces, ha sido presentada en distintos espacios de Santiago (museos, teatros, poblaciones, universidades y en la misma vía pública) y formatos que, además de la performance, incluye videos, conferencias, seminarios y el documental homónimo (2016) dirigido Mauricio Ahumada y escrito por la misma artista. En este trabajo todavía en curso, que se caracteriza por combinar distintas disciplinas y lenguajes artísticos, Huenchumil busca hacerse cargo de la pregunta por su filiación indígena, estableciendo cruces entre su propio relato autobiográfico, el proceso creativo en torno al cuerpo y el activismo.

Según lo explicado por Huenchumil al inicio del documental Warriache y también en su intervención en el Taller de Arte convocado por la Cátedra Indígena de la Universidad de Chile en el 2016, la inquietud acerca de su origen mapuche emerge mientras estudiaba en la universidad. Fue allí donde distintas personas le preguntaron si era o no mapuche, interrogante que le resultaba algo incómoda pues no sabía bien qué responder. Más allá del apellido paterno, por el cual era objeto de burla en la escuela, su relación o contacto con el mundo mapuche había sido prácticamente nula. Comienza, de esta manera, un proceso de subjetivación y construcción identitaria que se articula desde la práctica artística y su encuentro con el pensamiento mapuche. Cito un fragmento del texto "Warriache, el cuerpo como primer territorio"” en el que Huenchumil se refiere a esta situación:

Toda la vida me preguntaron si era mapuche y como debido a que en mi familia nunca se practicaron tradiciones, esa pregunta siempre me incomodó. No sabía si decir que sí o que no. Por un lado, si decía sí, ¿qué significaba ser mapuche? Por otro, si decía que no, sentía que negaba mi origen, pero, ¿podía negar lo que desconocía? (85).

\footnotetext{
${ }^{7}$ En el libro El bosque de la memoria se incluyen dos textos de Huenchumil que surgen en el contexto del Taller de Arte realizado en la Universidad de Chile. El texto "Warriache, el cuerpo como primer territorio" es una transcripción de su participación en una mesa de conversación y "Warriache" es una transcripción de la performance realizada en la misma ocasión.
} 
Las palabras de Huenchumil acerca de su desconocimiento sobre la cultura mapuche dan cuenta del desarraigo experimentado en su condición de mapuche urbana e hija de la diáspora. En este contexto de búsquedas y (des)encuentros, la artista comienza a elaborar y poner en escena la idea de su cuerpo como territorio, zona fronteriza y liminar que opera simultáneamente como una serie de presencias/ausencias que problematizan cualquier noción de purismo identitario. Reproduzco a continuación dos fragmentos del documental Warriache, en los que se hace visible este tránsito desde el cuerpo-territorio perdido al cuerpo-territorio warriache y mapuche:

Me sentí un cuerpo sin territorio. Un cuerpo con un territorio perdido y tomé más consciencia de mi cuerpo y decido presentarme como warriache. Y cuando me nombro así no les estoy diciendo que vivo en la ciudad. Les estoy diciendo que construyo mi territorio en el cuerpo. En mi propio cuerpo.

$[\ldots]$

Este cuerpo es presencia del cuerpo ausente. Soy cuerpo sin forma de tradición. Soy lengua que le enseńaron el ritmo del castellano. Soy cuerpo nacido en ciudad. Soy ausencia de tierra y presencia de despojo. Soy cuerpo de mezcla y presencia de encuentros. [...] Soy ausencia de fundamentalismos. [...] Soy cuerpo, boca, ojos, lengua y oídos de resistencia. Soy presencia de lucha en español. Soy un cuerpo de decisión. Yo soy mapuche (Huenchumil y Ahumada).

En el caso de las intervenciones performáticas de Warriache, esta puesta en escena del cuerpo como territorio perdido/recuperado se traduce en la realización de una secuencia de acciones, en las que Huenchumil juega con la presencia/ausencia de su propio cuerpo en el escenario y el recurso recurrente de la pregunta retórica dirigida hacia sí misma, su cuerpo y el público. Cito algunas preguntas a modo de ejemplo: “¿Un cuerpo sin territorio es un cuerpo perdido?”, “¿Se puede sentir la ausencia de uno mismo?”, "Cuerpo, ¿te perdiste tú o me perdí yo?” (Huenchumil 138).

Desde esta perspectiva, entiendo el trabajo performático de Huenchumil como un ejercicio de descolonización de su propia subjetividad y conocimientos que se realiza en/ desde/con el cuerpo, entendido no sólo como un soporte artístico de su obra, sino ante todo como un territorio en disputa que se reclama como propio, autónomo y soberano. En otras palabras, frente a la experiencia de exilio que implica habitar la Mapurbe, la artista busca reconstruir desde su propio cuerpo el vínculo erosionado con el territorio ancestral, su memoria y cultura. En este sentido, no resulta casual que Huenchumil haya optado por la performance para ir reconstruyendo su proceso identitario como mapuche. Esta práctica artística, que se caracteriza por ser abierta, efímera y siempre en proceso (Taylor 2011), se condice con la posibilidad de ir performando su propia identidad indígena desde el cuerpo y el espacio de la ciudad ${ }^{8}$. En otras palabras, Warriache demuestra que la condición

${ }^{8}$ A partir de la idea de performatividad del género propuesta por Judith Butler y a propósito del caso de 
de mapuche no viene dada por naturaleza o de una vez y para siempre, sino que implica un ejercicio permanente de actos identificación y reterritorialización. De ahí el gesto de autodeterminación que implica pensarse y nombrarse a sí misma como warriache.

En línea con lo anterior, el cuerpo también opera en la performance de Huenchumil como una apelación directa a los transeúntes y espectadores acerca de sus propios prejuicios sobre los mapuche. $\mathrm{Y}$ al decir esto me refiero, especialmente, a una de las acciones más emblemáticas de Warriache, "Mapuchómetro", y que nos remite a la gestación de este proyecto performático. Según lo explicado por Huenchumil en algunos videos, la primera fase de Warriache se llevó a cabo en la calle. En lugares como el Paseo Ahumada y la Plaza de Armas, las personas eran invitadas por la artista a responder las siguientes preguntas: ¿quién es un mapuche?, ¿cómo es un mapuche?, ¿qué hace un mapuche? Las respuestas eran escritas en cartones que luego Huenchumil colgaba en su cuerpo hasta cubrirlo por completo, despertando la curiosidad y extrañeza de quienes se encontraban con esta figura caminante algo anómala. "Mapuchómetro", acción que tiene su origen en la vía pública, es reproducida posteriormente en las puestas en escenas de Warriache. En dicha instancia, la artista vuelve a cubrir su cuerpo con los carteles, para luego desprenderse de ellos y hacer una suerte de cuestionario a los espectadores acerca de su identificación con el contenido escrito en los mismos. "¿Quién tiene los pies gordos? ¿Quién se considera flojo? ¿Quién es moreno?” (Huenchumil 139). Estos son algunos ejemplos de las preguntas formuladas por Huenchumil y que el público debe responder con un sí o con un no. Sin decirlo, la artista aplica el llamado mapuchómetro a sus espectadores, definido por el periodista Pedro Cayuqueo como "aquella maquinita que mide tu porcentaje de mapuchidad" $(215)^{9}$. Por cierto, la artista está realizando una parodia crítica de este test, en el que convergen fantasías puristas y estigmatizaciones raciales.

Como bien señala Huenchumil en el documental, los carteles ponen en evidencia "las ideas fijas" y "poco reflexionadas" (Huenchumil y Ahumada) que los chilenos tienen acerca de los mapuche. "Queman", "violencia", "flojos", "ladrones", "borrachos", "morenos", "pies gordos" y "polarizados" son algunos de los calificativos escritos por los transeúntes, que dan cuenta de un "archivo de la representación racializada" todavía vigente (Hall 139) y de las nuevas "barbaries" que los discursos mediáticos, jurídicos y políticos atribuyen a los mapuche movilizados políticamente. En este sentido, cuando la artista porta dichos carteles sobre su cuerpo vuelve visibles, por un lado, que el principio de la raza (Mbembe 106) se sostiene en los actos de nombrar, clasificar y jerarquizar, y por otro, los dispositivos de racialización y el deseo de otredad que movilizan la matriz visual colonial-occidental (Barriendos 2011).

Rachel Dolezal, Marquis Bey y Theodora Sakellarides proponen entender la identidad racial como un acto performativo: "Racial identity, as performative, is a series of acts -speech, bodily, visual, political- that culminate into an identity. It is not something one $i s$; it is something one does" (43).

${ }^{9}$ Cayuqueo atribuye el origen del mapuchómetro al cómic de Pedro Melinao disponible en http://twitpic. com/4qca41 
En este contexto, el cartel escrito por un transeúnte que dice "No tiene carita de mapuche" ocupa un lugar relevante en la performance de Huenchumil. La artista comprende que su cuerpo no cumple con los estándares fenotípicos del llamado mapuchómetro y polemiza abiertamente con la idea de una identidad indígena pensada desde la ficción biológica de la raza, es decir, con la idea de que para ser mapuche habría que tener ciertos rasgos físicos. $\mathrm{Al}$ respecto, resulta inevitable recordar el controvertido caso de la activista afroamericana Rachel Dolezal, acusada públicamente hace algunos años de fingir ser una mujer negra cuando era blanca y que puso sobre la mesa el debate en torno a la identidad transracial. Lo que hace la performance de Huenchumil es, justamente, problematizar aquellas concepciones identitarias puristas y estáticas, apostando más bien por la posibilidad de repensar su condición de mujer mapuche desde el espacio de la ciudad y su devenir warriache. El cuerpo, en este sentido, se erige en un territorio perdido que debe ser recuperado, pero también en un territorio en resistencia, abierto, por performar y resignificar.

\section{Daniela Millaleo: Cantar y Recobrar el wallmapu}

Daniela Millaleo -cantautora, profesora de historia, integrante del colectivo Epew y nacida en la población Santa Julia de Santiago- lanzó su primer disco, Trafun, en el 2013. Desde entonces ha colaborado con su música en producciones audiovisuales como la película Mala junta (2016) de Claudia Huaiquimilla y el documental Río Sagrado (2019) de Nicole Ellena y Erick Vigouroux, así como en el concierto teatralizado Nüngen Zoológicos humanos (2019) del colectivo Epew, trabajo por el cual fue nominada recientemente a los premios Pulsar 2020 en la categoría premio a la difusión de la música de los pueblos originarios. También ha participado activamente en distintos eventos culturales vinculados a los movimientos mapuche, feminista y en defensa del agua, que dan cuenta de su férreo compromiso con las demandas territoriales y políticas de su pueblo. Junto con lo anterior, Millaleo se encuentra trabajando actualmente en el lanzamiento de su disco Wanglen, del cual ya ha dado a conocer algunos sencillos como "Vengo del sur", "Canción para Rayen", "Wanglen" y "Cerca del Toltén" en su canal de Youtube.

$\mathrm{Al}$ igual que Catrileo y Huenchumil, las letras de Millaleo ponen en escena la experiencia de desarraigo de los mapuche urbano. En la canción "Cerca del Toltén", por ejemplo, la voz imagina con nostalgia el regreso a las tierras originarias del sur, asumiendo una enunciación colectiva que remite a la idea de una comunidad unida en la experiencia del destierro y el deseo de volver al Wallmapu:

Y en el gris inerte nosotros danzamos en luz de luciérnaga

luces de asfalto recordamos nuestra esencia. 
$\mathrm{Y}$ contadas veces

juntamos los libros en nuestras maletas

para volar juntos

de regreso a nuestra tierra (Millaleo 2015: s/p).

Como habitante de ese "gris inerte" que es la ciudad, Millaleo busca recobrar el Wallmapu a través del canto y su guitarra, nutriéndose libremente de la tradición de la cantautoría chilena iniciada en los años 60 (González et al. 395; García 102) e incorporando algunos elementos de la música tradicional mapuche ${ }^{10}$. Ahora bien, si durante la Nueva Canción Chilena cantautores de origen campesino como Víctor Jara o Violeta Parra introdujeron en algunas de sus composiciones temáticas y sonoridades relativas al mundo mapuche (Carreño 206), con Millaleo nos enfrentamos a una cantautora que se referirá desde dentro y con voz propia a la situación colonial que hoy sigue viviendo el pueblo mapuche. Desde esta perspectiva, identifico en las letras de sus canciones al menos dos temáticas centrales: por un lado, la denuncia de la violencia de Estado ejercida sobre las comunidades mapuche y, por otro, la exaltación de la naturaleza del territorio ancestral amenazada por el capitalismo extractivista.

En coherencia con lo anterior, y lejos de cualquier fantasía cercana a una arcadia perdida, la cantautora visibiliza en las canciones "Trafun" y "Werken" la represión policial vivida en Wallmapu ${ }^{11}$. Para esto incorpora recursos de carácter documental y testimonial que dan cuenta de la violencia ejercida por el Estado chileno en dicho territorio. Me refiero a la reproducción de gritos, disparos y testimonios de dirigentes mapuche acerca de los allanamientos sufridos en sus comunidades ${ }^{12}$. Un claro gesto de denuncia política en contra de la persecución del movimiento de resistencia mapuche y la militarización del territorio ancestral, que a su vez coexiste con la reivindicación de la lucha del pueblo mapuche por su libertad. Cito, a modo de ejemplo, un fragmento de "Trafun":

Sangre de mi gente, mi gente que lucha

$[\ldots]$

yo tengo esa sangre, esa sangre en las venas

de gente que vive entre balas y penas

\footnotetext{
${ }^{10} \mathrm{Al}$ respecto, un ejemplo paradigmático lo constituye la canción "Nacido indio" de Trafun.

${ }^{11}$ Según Millaleo en El ciudadano, el disco Trafun -en el cual se incluyen ambas canciones- debe su nombre a una comunidad mapuche cercana a la localidad de Panguipulli, donde le tocó ser testigo de la represión policial: "yo una vez fui a ver un asunto de trabajo, fui a ver cómo hacían educación multicultural, que es mi área, y me pillé con pacos, con perdigones [...] yo vi un niño con un perdigón en la garganta y ahí quedé plop; una cosa es ver la represión por la TV y otra vivirla".

${ }^{12}$ Este gesto de Millaleo nos retrotrae al disco La Población (1972) de Víctor Jara. En esta obra emblemática de la música popular chilena, el cantautor incorporó grabaciones de los testimonios de los pobladores que él mismo registró en algunas tomas de terreno de Santiago como Herminda de la Victoria.
} 
de hombres que gritan llorando a los muertos

la sangre de un pueblo regada en el suelo.

Y buscar libertad

de mi pueblo que ahora reza

que se muere en la pobreza

y cantar en señal

que hemos roto las cadenas (Millaleo 2013: s/p).

Palabras como "sangre", "balas", "muertos", "pobreza" y "cadenas" vienen a confirmar que el Estado chileno ha instalado una soberanía cada vez más próxima a la muerte o necropolítica (Mbembe 2001) en el territorio de Wallmapu. Desde el retorno a la democracia, lo anterior se vuelve evidente en la aplicación de la Ley Antiterrorista a los mapuche movilizados y el encarcelamiento -e incluso muerte- de activistas indígenas y autoridades ancestrales. En este sentido, no es casual que Millaleo haya decidido rescatar en su canción "Werken" la figura del mensajero mapuche, autoridad ancestral que en los tiempos actuales continúa cumpliendo un importante papel político y social como vocero de las comunidades ${ }^{13}$. La artista le crea una voz y lo sitúa como un mediador entre los ancestros y sus coetáneos, cuya misión es llevar un mensaje de esperanza a su pueblo-nación.

Pero el Wallmapu también es recobrado en la música de Millaleo por su naturaleza y los saberes mapuche asociados a esta. Desde el exilio de la ciudad, la cantautora rememora en distintas canciones de Trafun y Wanglen el paisaje del sur, con especial énfasis en sus mares, ríos y los seres maravillosos - como las sirenitas de Mehuín- que habitan las aguas. En este contexto, el río Toltén tendrá una especial presencia en algunas de sus composiciones. En la canción "Ko (Agua)", por ejemplo, el reencuentro con el río es representado como una experiencia gratificante y sanadora. Al navegar por el Toltén, la voz se siente compenetrada con el agua y sus distintas manifestaciones. Su fluir libre, sonoro y lleno newen moviliza y potencia su canto:

Voy remando tan contenta en el Toltén veo agua desde el cielo, veo llover y es el boldo que me tomo como lawen.

Del estero hacia el río y después al mar es el agua que da vida a mi cantar no tan solo limpia el cuerpo, limpia el mar (Millaleo 2013: s/p).

\footnotetext{
${ }^{13}$ A propósito de su instalación Werken, el artista visual Bernardo Oyarzún explica en el reportaje de Elisa Massardo que el werken "Es un miembro de la comunidad muy importante, es el consejero del lonko y portador de la palabra política y social de una colectividad. Es el encargado de transmitir los mensajes y representar a la comunidad en los conflictos o en las relaciones intercomunales, es un extraordinario orador, mediador y trasmisor de los comunicados" (s/p).
} 
El agua es fuerza creativa, pero también lawen, al igual que el boldo.

Como podemos ver, estamos en presencia de una experiencia vital y afectiva con las aguas, que se condice con el apoyo entregado públicamente por Millaleo a las organizaciones sociales y comunidades mapuche que en el 2019 se movilizaron en contra de la construcción de la central hidroeléctrica Los Aromos en el río Toltén, específicamente, en el sector de Pitrufquén. Lejos de pensar el agua como una mercancía que debe ser aprisionada en una represa para su comercialización, la cantautora deja entrever en sus canciones y discursos públicos una mirada enraizada en las epistemologías y éticas indígenas de Wallmapu, donde el agua es vivida y pensada como una entidad viva, sagrada y libre que debe ser protegida. "Queremos todos volver a nuestras tierras. Especialmente yo quiero volver cerca del río Toltén, pero de un Toltén sin represas" (Millaleo 2015: s/p), dijo la cantautora antes de interpretar "Cerca del Toltén" en el concierto Canto a las 13 lunas, dando cuenta de su oposición a los proyectos extractivistas que amenazan la biodiversidad del territorio ancestral.

En este sentido, resulta importante mencionar también la canción "Wanglen", que da nombre al próximo disco de Millaleo, donde la cantautora rescata un epew mapuche que atribuye el origen de las creaciones terrestres a una estrella que, al caer del cielo, se convierte en una mujer que da vida a distintos seres y manifestaciones de la naturaleza: "Dicen que cayó de una estrella/ a iluminar la tierra entera./ [...] pariendo ríos, bosques y selvas". Según lo explicado por la misma artista ${ }^{14}$, con esta canción ella realiza un homenaje a todas las mujeres que luchan contra la violencia patriarcal ejercida sobre sus cuerpos y el de la naturaleza, resignificando, de esta manera, los relatos ancestrales mapuche desde una perspectiva feminista que bien podríamos identificar, incluso, con el ecofeminismo ${ }^{15}$. Cito un fragmento de la letra de "Wanglen" que da cuenta de esta imbricación entre los saberes indígenas y el feminismo en el trabajo de Millaleo:

En el transcurso de la historia caen estrellas paridoras.

Recorren surcos y ciudades para engendrar nuevas libertades.

Semillas libres de violencia

purificando todo el planeta.

Revoluciones desde el vientre

de una mujer que es de la tierra (Millaleo 2015: s/p).

La lucha de las mujeres indígenas por sus territorios y el autosustento para sus comunidades, tantas veces invisibilizada en los relatos históricos oficiales, se metaforiza en esta canción en las "estrellas paridoras". Son las mujeres en resistencia que protegen

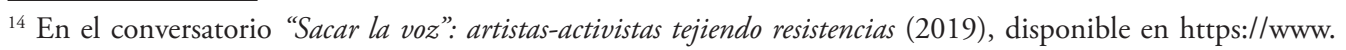
youtube.com/watch?v=sYBNnft9amc\&t=584s

15 
las distintas formas de vidas -humanas y no humanas- amenazadas por el patriarcado capitalista (Shiva). Son las defensoras de los ríos y las guardianas de semillas que propician la autonomía de sus pueblos y el cuidado del planeta. De ahí la revalorización del vínculo entre mujeres y naturaleza, pero ya no desde una mirada patriarcal ni colonial, sino que desde un posicionamiento indígena, feminista y abiertamente político, que nos invita a pensar la tierra como una Nuke Mapu capaz de engendrar vida y "revoluciones".

\section{A MODO DE CIERRE: SANTIAGO WARIA}

En el año 2016, Bernardo Oyarzún montó su exposición Mitomanias: relatos de la imaginación en la galería Patricia Ready. En una de las instalaciones, el artista visual realizó un gesto transgresor: propuso reemplazar la estatua de Pedro de Valdivia de la Plaza de Armas de Santiago por una escultura a gran escala que reproducía la figura del camélido de oro encontrada en la tumba del Niño del Plomo, quien fue enterrado vivo en tiempos del Tawantinsuyu en el marco de la ceremonia llamada capacocha. A través de este acto de inversión simbólica, Oyarzún nos invitaba a deconstruir la historia colonial sobre la fundación de Santiago y a visibilizar las raíces indígenas -en este caso incaicas- sobre las cuales se construyó nuestra ciudad. Poco tiempo después, en el marco del estallido social, el 6 de noviembre de 2019 la estatua del conquistador y gobernador de Chile fue intervenida y carnavalizada por distintas organizaciones indígenas. Esta acción cultural por el derecho a la autodeterminación y la redacción de una constitución plurinacional ${ }^{16}$, se suma a la serie de actos ciudadanos en que estatuas y monumentos de distintas partes de Chile y el mundo han sido derribadas o destruidas.

Pienso que las producciones de Catrileo, Huenchumil y Millaleo realizan un gesto similar a los descritos anteriormente. Como propusimos al inicio de este ensayo, sus obras pueden ser entendidas como recados descolonizadores que, desde una discursividad abigarradamente mestiza o chixi, nos invitan a desaprender las "mitomanías" coloniales que configuran nuestras formas de vida y a repensar nuestra capital como un territorio indígena en resistencia. Desde los lenguajes de la escritura, el cuerpo y el canto, las tres artistas nos recuerdan que nuestros pies caminan sobre una ciudad que hace ya quinientos años fue quemada por Michimalonco en un acto de rebelión contra la invasión española. Una ciudad que lleva inscrito en los nombres de sus cerros y ríos la historia viva del pueblo mapuche y de aquellos hijos y nietos de la diáspora que hoy reconstruyen sus memorias, filiaciones y afectos ancestrales reivindicando su condición de champurria. Descolonizar, entonces, también implica abrir la posibilidad de pensar las identidades culturales desde un posicionamiento no purista ni esencialista, que emerge desde la herida colonial y una zona liminar o fronteriza en la que se entrecruzan -por cierto con conflictos y tensiones-

\footnotetext{
${ }^{16}$ Sobre esta intervención cultural, se recomienda consultar el artículo de Paula Huenchumil y Catalina Mondaca publicado en Interferencia. Ver la referencia completa en la bibliografía.
} 
temporalidades y culturas heterogéneas, pero también las memorias de una historia de resistencias y luchas que aún se siguen escribiendo en las calles de la Mapurbe.

Para terminar, también me parece importante relevar el posicionamiento de género de las producciones aquí analizadas. En coherencia con una mirada interseccional, lo que hacen Catrileo, Huenchumil y Millaleo es poner en escena las voces y cuerpos de mujeres racializadas que hasta ahora habían tenido escasa visibilidad en el campo artístico mapuche y chileno: las warriache. Ya no estamos hablando de María Juana la mapunky de La Pintana imaginada y escrita por Aniñir, sino de mujeres mapuche nacidas en la ciudad que han optado por escribir, performar y cantar sus propias y diversas historias de exilio, pertenencia y despojo. Desde el lugar imaginario que es la creación artística, las tres buscan reconstruir y resignificar las filiaciones mapuche erosionadas por la violencia colonialpatriarcal, reterritorializándose en las aguas movedizas de la escritura (Catrileo), el cuerpo que no cumple con los estándares del mapuchómetro (Huenchumil) y el canto que permite recobrar -desde la ciudad- el territorio de Wallmapu (Millaleo). La Mapurbe, entonces, emerge en estas producciones desde consciencias descolonizadoras y en estrecho diálogo con los feminismos indígenas de los Sures del mundo.

\section{OBRAS CITADAS}

Ahumada, Mauricio (director). 2016. Warriache. Guión y actuación de Camila Huenchumil. Cine Chile. http://cinechile.cl/pelicula/warriache-2/

Aniñir, David. 2005. Mapurbe. Venganza a raíz. Santiago: Odiokracia Autoediciones.

Antileo, Enrique. 2012. "Migración Mapuche y continuidad colonial”. Ta iñ fijke xipa rakizuameluwün. Historia, colonialismo y resistencia en el pais Mapuche. Comunidad de Historia Mapuche. Temuco: Ediciones Comunidad de Historia Mapuche.

Anzaldúa, Gloria. 2016. Borderlands/La Frontera. La nueva mestiza. Trad. Carmen Valle. Madrid: Capitán Swing.

Barriendos, Joaquín. 2011. "La colonialidad del ver. Hacia un nuevo diálogo visual interepistémico". Nómadas 35: 13-29.

Barros, María José. 2009. "La(s) identidad(es) mapuche(s) desde la ciudad global en $M a-$ purbe venganza a raiz de David Aniñir". Revista Chilena de Literatura 75: 29-46.

Bey, Marquis y Sakellarides, Theodora. 2016. "When We Enter: the Blackness of Rachel Dolezal". The Black Scholar 4: 33-48.

Calfuqueo, Sebastián. 21 sep 2017. "Mürke ko (Agüita con harina tostada)”. Sebastián Calfuqueo. Disponible en: https://sebastiancalfuqueo.com/2017/09/21/murke-koaguita-con-harina-tostada/mu\%CC\%88rke-ko-detalle/

Carreño, Rubí. 2013. Av. Independencia. Literatura, música e ideas de Chile disidente. Santiago: Cuarto Propio.

Catrileo, Daniela. 2016. Rio herido. Santiago: Edicola. . 26 sep 2019. "Merodeos en torno a la potencia champurria". Medio rural. http:// 
mediorural.cl/merodeos-en-torno-a-la-potencia-champurria/

. 13 mar 2019. "Daniela Catrileo, poeta: "Voy construyendo nuestra identidad a punta de esquirlas y memorias comunes". Entrevista por María Jesús Blanche. Biblioteca Viva. http://mediorural.cl/merodeos-en-torno-a-la-potencia-champurria/

Cayuqueo, Pedro. 2012. "El mapuchómetro". Solo por ser indios y otras crónicas. Santiago: Catalonia.

Espinosa, Patricia. 11 ene 2018. "De frente contra el daño y el exterminio". Palabra Pública. https://palabrapublica.uchile.cl/2018/01/11/rio-herido-de-daniela-catrileo-defrente-contra-el-dano-y-el-exterminio/

García, Marisol. 2013. Canción valiente 1960-1989. Tres décadas de canto social y politico en Chile. Santiago: Ediciones B.

González, Juan Pablo, Ohlsen, Óscar y Rolle, Claudio. 2009. Historia Social de la Música Popular en Chile, 1950-1970. Santiago: Ediciones UC.

Hall, Stuart. 2010. "El espectáculo del 'Otro'”. Sin garantías. Problemáticas y trayectorias en estudios culturales. Ed. Eduardo Restrepo, Catherine Walsh y Víctor Vich. Popayán: Envión Editores.

Huenchumil, Camila. 2017. "Warriache, el cuerpo como primer territorio" y "Warriache". El bosque de la memoria. Reflexiones y testimonios sobre arte indígena. Varios(as) Autores(as). Santiago: Equipo Cátedra Indígena, Universidad de Chile.

Huenchumil, Paula y Mondaca, Catalina. 8 nov 2019. "Derribar símbolos coloniales: Un nuevo acto político que se suma en las protestas en Chile". Interferencia. Recuperado de: https://interferencia.cl/articulos/derribar-simbolos-coloniales-un-nuevo-actopolitico-que-se-suma-en-las-protestas-en-chile

Llamunao Vega, Carla. 2020. "Lectura/escritura Champurria. Un posicionamiento metodológico para el estudio de poesía mapuche". Revista Documentos Linguísticos y Literarios UACh 39: 151-164. Recuperado de http://www.revistadll.cl/index.php/ revistadll/article/view/426/559

Lemebel, Pedro. 2013. "Zanjón de la Aguada (crónica en tres actos)". Poco hombre. Santiago: Ediciones UDP.

Mariman, Pablo, Caniuqueo, Sergio, Millalén, José y Levil, Rodrigo. 2006. i...Escucha, winka...! Cuatro ensayos de Historia Nacional Mapuche y un epilogo sobre el futuro. Santiago: Lom.

Massardo, Elisa. 5 ago 2018. Bernardo Oyarzún. Cada obra es una utopía. https://www. arteallimite.com/2018/08/05/bernardo-oyarzun-cada-obra-es-una-utopia/

Mbembe, Achille. 2011. Necropolitica seguido de Sobre el gobierno privado indirecto. Trad. Elisabeth Falomir Archambault. España: Melusina. . 2016. Crítica de la razón negra. Ensayo sobre el racismo contemporáneo. Trad. Enrique Schmukler. Ulzama: Ned Ediciones.

Millaleo, Daniela. 5 jul 2015. "Cerca del Toltén". Canal Daniela Millaleo Youtube. https:// www.youtube.com/watch?v=Jk2l-Bicba4 27 abr 2014. "Daniela Millaleo, cantautora mapuche: "Sin Resistencia nuestra 
cultura ya no existiría”. Entrevista por Wari. El ciudadano. https://www.elciudadano. com/entrevistas/daniela-millaleo-cantautora-mapuche-sin-resistencia-nuestra-cultura-ya-no-existiria/04/27/ . 2013. "Ko (Agua)". Trafun. Hijo del Salitre. . 2013. "Trafun". Trafun. Hijo del Salitre. . 3 jul 2015. "Wanglen". Canal Daniela Millaleo Youtube. https://www.youtube. com/watch?v=TnMrvSUbGBU

Moraga, Fernanda. 2009. "A propósito de la "diferencia": poesía de mujeres mapuche". Revista Chilena de Literatura 74: 225-239. . 2010. "La emergencia de un corpus poético de mujeres mapuche". Kümedungun/ Kümewirin. Antología poética de mujeres mapuche (siglos XX-XXI). Ed. Maribel Mora Curriao y Fernanda Moraga. Santiago: Lom.

Morales, Leonidas. 2011. "Gabriela Mistral: recados de la aldea". Revista chilena de literatura 80: 203-222.

Pairicán, Fernando. 2014. Malon. La rebelión del movimiento mapuche 1990-2013. Santiago: Pehuén.

Paredes Pinda, Adriana. 2005. "De por qué escribo... Mollfvñ pu nvtram”. Üi. Santiago: Lom. . 2017. "La pluma del picaflor del agua". Zomo Newen. Relatos de vida de mujeres mapuche en su lucha por los derechos indigenas. Coord. Elisa García Mingo. Santiago: Lom.

Poblete, Felipe. 12 abr 2017. "Río Herido (2011-2016), una memoria". Letras de Chile. https://www.letrasdechile.cl/home/index.php/comentarios-de-libros/269-rio-herido-2011-2016-una-memoria.html

Rivera Cusicanqui, Silvia. 2018. Un mundo chixi es posible. Ensayos desde un presente en crisis. Buenos Aires: Tinta Limón.

Sanjinés C., Javier. 2005. El espejismo del mestizaje. La Paz: Embajada de Francia; IFEA Instituto Francés de Estudios Andinos; Fundación PIEB.

Shiva, Vandana. 2001. Biopiratería. El saqueo de la naturaleza y del conocimiento. Barcelona: Icaria.

Taylor, Diana. 2011. "Introducción. Performance, teoría y práctica". Estudios avanzados de performance. Ed. Diana Taylor y Marcela Fuentes. México: FCE.

Zapata, Claudia. 2018. "Memorias de asfalto. Los mapuche urbanos en la poesía de David Aniñir Guilitraro". Taller de Letras 62: 69-82. 